\title{
Alimentos da agricultura familiar na alimentação escolar: percepções dos atores sociais sobre a legislação e sua implementação
}

Family farming products in school feeding: perceptions of social actors on the legislation and its implementation

\section{Aliments de l'agriculture familiale dans l'alimentation scolaire: perceptions des acteurs sociaux sur la législation et son application}

Alimentos de la agricultura familiar en la alimentación escolar: percepciones de los actores sociales sobre la legislación y su implementación

\author{
Márcia Pozzagnol Mossmann ${ }^{1}$ \\ Carla Rosane Paz Arruda Teo ${ }^{1}$
}

Recebido em 23/09/2016; revisado e aprovado em 25/03/2017; aceito em 19/04/2017

DOI: http://dx.doi.org/10.20435/inter.v18i2.1391

\begin{abstract}
Resumo: O estudo objetivou conhecer percepções de diferentes atores sociais sobre a Lei 11.947/2009 e sua implementação, nas questões da agricultura familiar. Trata de pesquisa qualitativa com 35 atores da alimentação escolar em 8 municípios catarinenses. A Lei foi percebida como vetor de alimentação saudável, fortalecimento da agricultura familiar, desenvolvimento local; sua implementação foi iniciativa dos gestores técnicos do programa. Recomenda-se incentivo à participação e protagonismo dos demais atores envolvidos.

Palavras-chave: desenvolvimento local; desenvolvimento rural; programas e políticas de nutrição e alimentação.

Abstract: The study aimed to identify perceptions of different social actors on the Law 11.947 / 2009 and its implementation with respect to family farming matters. This is a qualitative research with 35 social actors of school feeding in eight municipalities in Santa Catarina state. The Law was perceived as a vector for healthy eating, family farming strengthening, local development; its implementation was an initiative of the technical managers of the program. Encouraging the participation and leadership of other actors involved is recommended.
\end{abstract}

Key words: local development; rural development; food and nutrition programs and policies.

Résumé: Cette étude a eu pour objectif de connaître les perceptions de différents acteurs sociaux sur la loi 11.947/2009 et son application dans les questions de l'agriculture familiale. Elle traite d'une recherche qualitative avec 35 acteurs de l'alimentation scolaire dans 8 communes de l'État de Santa Catarina. La loi a été perçue comme un vecteur d'alimentation saine, un renforcement de l'agriculture familiale et du développement local ; son application a été une initiative des gestionnaires techniques du programme. On recommande l'encouragement à la participation et le protagonisme des autres acteurs concernés.

Mots-clés: developpement local; developpement rural; programmes et politiques de nutrition et de l'alimentation.

Resumen: El estudio tuvo como objetivo conocer las percepciones de diferentes actores sociales sobre la Ley $11.947 / 2009$ y su implementación, en las cuestiones de la agricultura familiar. Se trata de una investigación cualitativa con 35 actores de la alimentación escolar en 8 municipios catarinenses. La Ley fue percibida como vector de alimentación saludable, fortalecimiento de la agricultura familiar y desarrollo local; su implementación fue una iniciativa de los gestores técnicos del programa. Se recomienda incentivar la participación y el protagonismo de los demás actores involucrados.

Palabras clave: desarrollo local; desarrollo rural; programas y políticas de nutrición y alimentación.

\footnotetext{
${ }^{1}$ Universidade Comunitária da Região de Chapecó (UNOCHAPECÓ), Chapecó, Santa Catarina, Brasil.
} 


\section{INTRODUÇÃO}

O Programa Nacional de Alimentação Escolar (PNAE) é a mais longeva ação do Governo Federal brasileiro na área de alimentação e nutrição, eixo das políticas públicas do campo da segurança alimentar e nutricional (SANTOS et al., 2007). A aprovação da Lei n. 11.947/2009 (BRASIL, 2009) atualizou o marco legal do Programa, proporcionando avanços significativos, principalmente no que diz respeito à promoção da alimentação saudável. Conforme disposto em seu artigo 14, a Lei tornou obrigatória a aplicação mínima de 30\% dos recursos repassados pelo Fundo Nacional de Desenvolvimento da Educação (FNDE) aos municípios, na compra de alimentos da agricultura familiar (BRASIL, 2009; BRASIL, 2013). Evidencia-se, assim, uma intencionalidade de promover maior acesso a alimentos básicos in natura e redução da oferta de alimentos industrializados, de maior grau de processamento, por meio das refeições providas aos escolares atendidos pelo programa.

Além disso, essa legislação colocou em cena inovações relevantes no âmbito da simplificação das compras públicas e do fortalecimento da agricultura familiar. Sob esta perspectiva, o PNAE passa a representar uma via para os agricultores familiares comercializarem seus produtos, constituindo um novo e expressivo mercado institucional. O programa assume, então, característica de política pública estruturante, com repercussões importantes para o desenvolvimento local, para a proteção de grupos vulneráveis e para a reconfiguração do sistema alimentar, com potencial para impactar favoravelmente na saúde das populações (TRICHES; GERHARDT; SCHNEIDER, 2014).

Nesse ponto, cabe registrar que desenvolvimento local é um construto que pressupõe a inclusão social (SILVEIRA, 2010). Trata-se de um modelo de desenvolvimento que supera as abordagens focadas exclusivamente nos fenômenos econômicos, integrando dimensões sociais, políticas e ambientais (JARA, 1998). Logo, apoiar ou promover o desenvolvimento local é um processo que se fundamenta na potencialização dos recursos, ativos, oportunidades e capacidades locais, pela ação sinérgica dos diferentes atores presentes no território, mobilizados por objetivos compartilhados (PIRES, 2010). O desenvolvimento local não lida, em essência, com questões de escala, mas está associado a iniciativas de natureza participativa que mobilizam a coletividade na direção de reconhecer e articular as potencialidades locais para promover inclusão social (BUARQUE, 1999).

Nesse sentido, há que se considerar que a Lei n. 11.947/2009 possa ser implementada de maneiras diferentes, de acordo com a leitura que façam dela os diferentes atores sociais envolvidos, segundo as oportunidades que historicamente acessaram e de acordo com as capacidades que tenham desenvolvido, além dos interesses e disputas que estejam colocados em cena. Propõe-se, ainda, que essas diferentes leituras possam repercutir em situações mais ou menos exitosas no processo de dar materialidade à política. Diante desses argumentos, e visando à produção de elementos que possam favorecer avanços neste campo, o objetivo deste estudo foi conhecer as percepções de diferentes atores sociais sobre a Lei n. 11.947/2009 e sua implementação nas questões afetas à agricultura familiar.

\section{METODOLOGIA}

Realizou-se, em 2014, estudo descritivo de abordagem qualitativa com atores sociais envolvidos com a Lei n. 11.947/2009, em municípios de Santa Catarina. Para esse estudo, os municípios foram selecionados a partir de uma pesquisa mais ampla. Inicialmente, foram iden- 
tificados os municípios que haviam divulgado chamadas públicas para aquisição de alimentos da agricultura familiar para o PNAE em 2012 e 2013 (96 municípios). Destes, oito municípios foram selecionados para a etapa qualitativa da pesquisa, de forma que contemplassem um número de matrículas na rede municipal de ensino equivalente a, pelo menos, $10 \%$ do alunado do estado, além de ampla diversidade quanto ao porte populacional. Segundo esses critérios, os oito municípios selecionados atendiam o equivalente a 15,0\% do alunado do estado (INEP, 2012; 2013), sendo três deles classificados como muito pequenos (menos de 20 mil habitantes), dois como pequenos (entre 20 e 100 mil habitantes), dois médios (de 100 a 500 mil habitantes) e um de grande porte (acima de 500 mil habitantes), localizados nas Mesorregiões Oeste, Serrana e Norte (IBGE, 2011).

O grupo de sujeitos de pesquisa foi, assim, composto por 35 atores sociais envolvidos com o fenômeno em estudo nos municípios selecionados: oito nutricionistas responsáveis técnicos pelo PNAE, nove agricultores familiares, dez consumidores (membros do Conselho de Alimentação Escolar [CAE], professores, diretores, cozinheiras escolares), oito membros da Assistência Técnica e Extensão Rural (ATER). As entrevistas semiestruturadas foram realizadas individualmente, gravadas e transcritas. O material textual produzido foi explorado por análise de conteúdo temática (MINAYO, 2013), definindo-se duas categorias analíticas prévias: percepções sobre a Lei n. 11.947/2009- o que pensam diferentes atores sociais sobre a aquisição de alimentos da agricultura familiar para a alimentação escolar?; e Implementação da Lei n. 11.947/2009- transformando a letra da lei em realidade. No âmbito de cada uma das categorias prévias, buscou-se reconhecer as convergências, divergências e reiterações presentes nos depoimentos dos participantes, organizando-se a síntese resultante a partir de categorias temáticas que representam os núcleos de sentidos do conjunto das falas dos entrevistados.

O projeto que deu origem a este estudo foi aprovado por Comitê de Ética em Pesquisa Envolvendo Seres Humanos, sob parecer n. 1.207.443. A fim de preservar o anonimato dos participantes, seus municípios de origem foram identificados por letras $(A, B, C, D, E, F, G, H)$.

\section{RESULTADOS E DISCUSSÃO}

\subsection{Percepções sobre a Lei $n$. 11.947/2009: o que pensam diferentes atores sociais sobre a aquisição de alimentos da agricultura familiar para a alimentação escolar?}

Entre os primeiros elementos que surgiram das falas dos participantes, destaca-se a alimentação saudável, referida pelos atores como a oferta de alimentos com mais qualidade e livres de perigos químicos.

Eu acho que é uma forma de a gente garantir que as crianças recebam uma comida de mais qualidade, de forma mais fresca, que não precisa viajar longas distâncias. Então, é colhida lá no agricultor e, no dia seguinte, já está na escola. (Nutricionista, município A).

Nossa, a qualidade dos alimentos melhorou 100\%! E o incentivo, assim, de se alimentar com uma alimentação saudável, sem agrotóxico... A gente sabe que é um alimento daqui do município, né? E a gente tem uma consciência, assim, que está ingerindo alimentos mais saudáveis. (Consumidor, município $\mathrm{C}$ ).

Conforme ilustram as falas apresentadas, a Lei n. 11.947/2009 é percebida como uma possibilidade de melhorar a alimentação disponibilizada aos escolares, com a ampliação da oferta 
de alimentos básicos, tradicionais e in natura, considerados mais saudáveis por possuírem procedência conhecida, devido à produção ser local ou regional, o que lhes confere credibilidade. Além disso, também proporciona a oferta de alimentos mais frescos, tendo em vista a proximidade entre fornecedor e consumidor. Nesse sentido, salienta-se que a oferta de alimentos in natura, principalmente frutas e hortaliças, torna a refeição mais atrativa, pois este grupo contempla uma diversidade de sabores e colorações, agradando os sentidos e estimulando seu consumo. Isso é especialmente importante, na medida em que o consumo de frutas e hortaliças pela população brasileira é reconhecidamente muito baixo (LEVY et al., 2012), e a escola passa a ser um local estratégico para a oferta desses alimentos, incentivando as crianças desde pequenas a formarem hábitos alimentares saudáveis a partir da exposição frequente e intensiva a alimentos saudáveis (BRASIL, 2008).

Destaca-se, também, como uma alimentação saudável, a oferta de alimentos livres de agrotóxicos, que devem ser priorizados na compra da agricultura familiar para o PNAE, podendo, inclusive, ser melhor remunerados, com acréscimo de até 30\% do valor pago ao mesmo alimento com origem em produção convencional (BRASIL, 2013). A valoração dos orgânicos se fundamenta no fato de estes serem isentos de produtos químicos prejudiciais à saúde, além de apresentarem maior biodisponibilidade de micronutrientes (GONZALEZ-CHICA et al., 2013). No entanto, no município de origem do entrevistado que indicou, em sua fala, uma relação entre a compra de alimentos da agricultura familiar e a ausência de agrotóxicos, não são adquiridos alimentos orgânicos certificados. Essa observação sugere que pode estar se configurando um mito em torno do alimento produzido pela agricultura familiar, o que não contribui para o seu fortalecimento.

Registra-se, também, que as falas que remetem a uma percepção da Lei como oportunidade de promoção da alimentação saudável foram citadas, principalmente, pelos nutricionistas $(n=6)$ - provavelmente, devido ao seu conhecimento específico na área - e pelos consumidores $(n=5)$, entre os quais há uma merendeira e quatro membros do CAE, atores que possuem maior proximidade com o cotidiano do ambiente escolar. Para os agricultores ( $n=4)$, a alimentação saudável não foi um aspecto citado com ênfase com relação a sua percepção sobre a Lei. Contudo são apresentadas, a seguir, duas falas de agricultores que perceberam essa associação.

Está produzindo bem com menos produtos tóxicos. Melhora muito a educação e a qualidade, e as crianças não são prejudicadas. (Agricultor, município E).

Meu filho é aluno. Eu fui várias vezes presidente da APP e via que tinha aquele barzinho, e as crianças se entupiam daquelas coisas lá. Não tinham uma alimentação saudável. Então, eu acho que, nesse ponto, contribuiu muito. (Agricultor, município F).

A Lei n. 11.947/2009 também resulta, segundo os participantes deste estudo, em fortalecimento da agricultura familiar, tendo em vista que confere valoração social ao segmento, favorece a permanência do agricultor no campo e gera incentivos para que continue produzindo.

Eu acho que a Lei é muito importante porque valoriza o pequeno produtor daqui do nosso município, as pequenas famílias produtoras. (Consumidor, Merendeira, município F).

Eu acho que a Lei veio fortalecer a agricultura, né? A gente observava que tinha pouco incentivo para o filho do produtor ficar na agricultura e hoje está bem fortalecido. Era só o pai e, hoje, o filho ajuda, a filha, a nora. (Nutricionista, município G).

O fornecimento de alimentos para o PNAE surgiu como um novo mercado para o agricultor familiar, representando mais uma oportunidade de geração regular de renda. Essa participação 
no mercado institucional surge, então, como uma possibilidade de contribuir para a permanência do agricultor no campo, o que tem especial relevância frente à expressiva urbanização do País, decorrente da migração da população rural, principalmente da parcela mais jovem, em busca de novas oportunidades nos centros maiores (AZEVEDO; RIGON, 2010).

Eu acredito que a Lei é uma possibilidade para que se fortaleça a agricultura familiar, porque além de gerar renda para o agricultor, ainda leva muitos a fazerem mais investimentos, valorizando seu produto pela agregação de valor. Podem investir em agroindústrias. A gente vê evasão dos jovens do campo. Então, essa alternativa de renda contribui muito para que os jovens tenham motivação e permaneçam no campo. (ATER, município D).

Aumentou a renda, foi bom para nós. Senão, só o dinheirinho da aposentadoria! Se a gente não tivesse isso, não tem como viver só com a aposentadoria! Dá só para os remédios, a gente ia sair, com certeza. (Agricultor, município G).

A questão da permanência das famílias no campo foi citada principalmente pelas nutricionistas $(n=4)$, dada sua experiência com o programa e maior proximidade com os agricultores familiares. Essa contribuição da Lei foi também expressivamente reconhecida pelos próprios agricultores $(n=9)$. Surpreende, no entanto, que essas questões tenham sido pouco reportadas pelos atores da ATER ( $n=2)$, os quais, em tese, conhecem mais profundamente a realidade desse setor. Esses atores, em alguns municípios, evidenciaram certo distanciamento da agricultura familiar, tanto por apresentarem reduzido número de profissionais quanto por priorizarem o atendimento de outras demandas, de maior expressão na economia do município, acentuando a insuficiência de assistência técnica ao segmento.

Ressalta-se que, a cada ano, o mercado institucional do PNAE movimenta bilhões de reais, sendo atrativo para os agricultores e reafirmando seu potencial para contribuir com o enfrentamento e a superação, pelas prefeituras e comunidades locais, de problemas de ordem econômica, social, política e ambiental, dentre eles o êxodo rural (CARVALHO, 2009). Nessa direção, os avanços na execução e na gestão do PNAE no Brasil, no âmbito do planejamento e da compra dos produtos da agricultura familiar, foram determinantes para promover o fortalecimento tanto do programa quanto de grande parte das famílias agricultoras (SARAIVA et al., 2013).

Dentre os principais benefícios da parceria entre agricultura familiar e alimentação escolar, merecem ser destacados o aumento da produção e de sua diversificação, a melhoria na renda e na qualidade de vida dos agricultores, a redução do êxodo rural, além de maiores investimentos na produção e aumento da formalização dos produtores com a participação em cooperativas e adesão ao PNAE. O Programa se caracteriza, assim, como uma possibilidade de fortalecer a economia local, integrando agricultor e consumidor a partir das compras públicas, oportunizando ao aluno conhecer a origem do alimento consumido e levando essa discussão para a escola por meio de atividades de educação alimentar e nutricional (TURPIN, 2009).

A partir do exposto, indica-se que as falas ressaltam a percepção dos atores com relação ao fortalecimento da agricultura familiar por meio da valorização dos agricultores e da geração de renda como vias de incentivo para a sua permanência no campo. Como convém a uma análise que reconhece a complexidade do fenômeno sobre o qual se debruça, é imperativo que se registre, neste ponto, que os elementos colocados em cena no âmbito do fortalecimento da agricultura familiar estão em íntima relação com a perspectiva do desenvolvimento local, categoria temática que também emergiu da análise das entrevistas. Nessa linha de pensamento, os participantes indicaram perceber a Lei n. 11.947/2009 como facilitadora do desenvolvimento da agricultura 
do município e da circulação de mercadorias e renda. Sublinha-se que essa percepção encontra suporte no artigo 20 da Lei, que explicita o incentivo ao desenvolvimento dos municípios, ao determinar que seja conferida prioridade para a aquisição de alimentos da agricultura familiar em sua área de abrangência.

Com relação à compra de no mínimo $30 \%$ eu acho excelente! Acho que vai contribuir muito para o desenvolvimento local lá onde eu trabalho. (Nutricionista, município B).

Desenvolvimento regional, eu acho que é isso, porque o agricultor produz e, ao mesmo tempo, ele potencializa que os vizinhos ajudem nesse processo. Ou os vizinhos produzem também e eles se articulam e vendem em conjunto. Vão expandindo as relações de mercado. É crescimento local e regional. (ATER, município A).

Ainda antes da obrigatoriedade estabelecida pela Lei n. 11.947/2009, já havia sido reconhecido que políticas públicas como o Programa de Aquisição de Alimentos (PAA) e o PNAE auxiliam no desenvolvimento local endógeno, visto que favorecem a reinserção econômica e social dos agricultores familiares (ALMEIDA et al., 2006). Nesse sentido, as falas apresentadas fundamentam a percepção de promoção do desenvolvimento local, na medida em que sinalizam

[...] um processo endógeno [...] capaz de promover o dinamismo econômico e a melhoria da qualidade de vida da população. Representa uma singular transformação nas bases econômicas e na organização social em nível local, resultante da mobilização das energias da sociedade, explorando as suas capacidades e potencialidades específicas. (BUARQUE, 1999, p. 9).

Destaca-se, ainda, da fala do ATER, a evidência do estabelecimento de alianças entre os agricultores, as quais - na perspectiva de Amartya Sen (2010), que propõe o desenvolvimento como expansão de liberdades - propiciam a criação de oportunidades para que as capacidades dos diferentes atores sejam fortalecidas e exercidas, em um movimento de redução das privações que limitam as escolhas e as oportunidades das pessoas. Esclarece-se que o incentivo ao desenvolvimento local sustentável se dá priorizando a compra de produtos diversificados, orgânicos ou agroecológicos, produzidos em âmbito local e, sempre que possível, por grupos mais vulneráveis. A ideia central é promover condições básicas para o fortalecimento e a diversificação da economia local, gerando emprego e renda e valorizando as especificidades e hábitos alimentares locais (BRASIL, 2016), contribuindo para o amadurecimento da consciência ambiental em uma dinâmica intergeracional. As falas dos atores sociais evidenciam a percepção de que a Lei atende a essas premissas, o que foi mais expressivo entre os nutricionistas gestores do Programa ( $n=3)$, e entre os entrevistados da ATER ( $n=3$ ), possivelmente por terem construído maior clareza sobre a Lei e seus desdobramentos. No entanto, também entre agricultores $(n=1)$ e consumidores $(n=1)$, essa compreensão esteve presente, embora de forma menos contundente.

E gira dinheiro no município, né? (Agricultor, município C).

Eu acho que é muito importante no sentido de que ajuda o município, o retorno para os nossos colonos. (Consumidor, Professor/Membro do CAE, município H).

Sem dúvida, o PNAE favorece a dinamização da economia local, destacando-se a relevância de reconhecer a atuação interdependente das diversas pastas do poder executivo envolvidas com o tema do desenvolvimento local, tais como educação, agricultura, administração, entre outras. O desenvolvimento local será potencializado na medida em que o gestor público consiga efetivar 
a aquisição de alimentos da agricultura familiar como uma ação verdadeiramente transversal no âmbito de políticas públicas setoriais, antecipando-se aos desafios, dentre os quais destacam-se a assistência técnica, questões de logística e armazenamento, diagnóstico e interação com a situação agrícola do município e região e, principalmente, a criação de fóruns participativos para debate e planejamento, envolvendo gestores, agricultores e escolas (SARAIVA et al., 2013). Isso significa dizer que é fundamental que os diferentes atores e setores estejam comprometidos com objetivos comuns compartilhados em uma lógica essencialmente participativa (DOWBOR, 2010).

\subsection{Implementação da Lei n. 11.947/2009: transformando a letra da lei em realidade}

A fase de implementação corresponde a um conjunto de processos por meio do qual os objetivos de uma política pública são realizados. É um movimento em que aquilo que foi programado, na formulação da política, é continuamente adequado às situações que precisam ser enfrentadas na realidade da prática. Assim, essa etapa é, nornalmente, bastante complexa (SUBIRATS et al., 2008), tendo sido identificadas, na análise das entrevistas, as seguintes categorias temáticas: iniciativa, mobilização e participação.

A iniciativa - o desencadear do processo em cada município - foi, basicamente, dos nutricionistas responsáveis pelo PNAE. Os atores destacaram que, a partir da aprovação da Lei n. 11.947/2009, as prefeituras, representadas pelos nutricionistas vinculados às Secretarias de Educação, iniciaram esse movimento.

Quando eu comecei a trabalhar aqui, em 2010, eu tomei conhecimento que tinha que adquirir. Então, comecei a pesquisar, me informar, falei com o setor de compras, mas não houve nenhuma mobilização, tanto que eu nem sabia de onde partir. (Nutricionista, município B).

O nutricionista, em virtude de sua formação específica, é o profissional que tem, por atribuição legal, a responsabilidade técnica pela gestão do PNAE (BRASIL, 2006; 2010). Cabem a esse profissional as diversas ações implicadas na execução do programa, o que pode explicar o fato de ter sido mencionado, neste estudo, como o principal ator envolvido com a iniciativa de implementar a Lei n. 11.947/2009. Os entrevistados ( $n=15)$ mencionaram que os nutricionistas assumiram a busca pelos agricultores, o mapeamento da produção local e todas as demais etapas do processo de aquisição dos alimentos, incluindo o movimento de articulação intersetorial no âmbito do município. Situação semelhante foi relatada em estudo anterior sobre o tema (SOARES et al., 2015), que indicou que esse ator social adotou um movimento de aproximação e diálogo, iniciando o processo.

No ano que a Lei foi publicada, a prefeitura procurou a cooperativa e foi feito contato com os agricultores. A gente conseguiu já fazer o primeiro projeto. (Agricultor, município D).

Os responsáveis foram o setor de alimentação e, em particular, um agricultor, que trouxe a cooperativa para participar da alimentação escolar, do PNAE. (Nutricionista, município H).

A fala do nutricionista do município H ressalta a participação do agricultor como elemento fundamental, pois favoreceu que outros agricultores se inserissem como fornecedores do PNAE.

O pessoal ali da merenda, das escolas, lá do sindicato, foi lá através da Secretaria da Agricultura, lá da Epagri². (Agricultor, município F).

\footnotetext{
${ }^{2}$ Empresa de Pesquisa Agropecuária e Extensão Rural de Santa Catarina.
} 
Na percepção do agricultor, a iniciativa foi uma ação da escola, por parte do nutricionista e, em alguns locais, foi destacada a participação da Secretaria de Agricultura e da Epagri, buscando se adequar à Lei e promover a inclusão dos alimentos da agricultura familiar na alimentação escolar, entrando em contato com os agricultores dos municípios e realizando a divulgação do programa.

A mobilização refere-se às ações efetivadas para desencadear efetivamente a implementação da Lei nos municípios, ressaltando-se, principalmente, a divulgação da legislação, o mapeamento da produção local e a realização de adequações exigidas pelo programa como estratégias utilizadas para colocar em movimento os diversos atores envolvidos em cada localidade. A divulgação da Lei foi considerada fundamental, segundo os participantes deste estudo, que indicaram a veiculação de informações pelas rádios da região e pela realização de reuniões pelas prefeituras e cooperativas.

Aqui, a divulgação acontece muito através da rádio, que é o meio de comunicação que os agricultores têm mais acesso. (Nutricionista, município C).

A fala acima revela que os municípios iniciaram um movimento no sentido de divulgar as mudanças ocorridas no PNAE e a possibilidade de inclusão dos agricultores familiares nesse mercado como fornecedores regulares. A veiculação de informações por meio de programas de rádio locais como dispositivo de comunicação com a comunidade rural é uma alternativa interessante, já que a maioria dos agricultores utiliza essa mídia. Reconhecendo a dinâmica do cotidiano rural, a legislação prevê o emprego desse recurso (BRASIL, 2015), considerado especialmente útil quando se espera alcançar os agricultores individuais.

Foi através da nossa cooperativa, que a gente teve reunião e o pessoal vinha avisando e a gente foi atrás. (Agricultor, município F).

As cooperativas também foram citadas como recurso de divulgação, visto que elas têm acesso facilitado às informações e que têm por meta ampliar progressivamente sua capacidade de abrangência e fornecimento, o que se dá pela prospecção das mais diversas oportunidades de inserção e comercialização, assim como pela ampliação de seu quadro de associados. Além disso, os agricultores cooperados que fornecem para o PNAE atuam como multiplicadores de informação entre seus pares.

São feitas reuniões com a prefeitura, antes de divulgar a chamada, para eles conhecerem junto das entidades, os produtores, para saber o que cada um está entregando. (ATER, município D).

As reuniões também foram destacadas como estratégicas para iniciar o processo de mobilização, possibilitando esclarecer objetivos e funcionamento do programa, além de responder a questionamentos e dúvidas dos agricultores. Assim, constatou-se que, para os entrevistados $(n=9)$, a divulgação foi um fator relevante para que os agricultores tomassem conhecimento da Lei n. 11.947/2009 e da possibilidade de se inserirem nesse mercado. A questão de conhecer a vocação agrícola dos municípios também foi considerada importante para a mobilização nos locais pesquisados.

A primeira coisa foi conhecer a realidade do município, fazer o mapeamento e a adequação dos produtos para que eles, de fato, atendessem às características mínimas que a gente exige no edital. Então, foi feito primeiramente um mapeamento dessa produção, para depois começar a pensar o que poderia colocar no cardápio e fazer a compra posteriormente. (Nutricionista, município D). 
Os nutricionistas ressaltaram que, para desencadear o processo de mobilização, era necessário conhecer a realidade local e a produção agrícola do município. Esse movimento, iniciado por alguns nutricionistas, evidencia a inversão da lógica de execução do programa, que - até então - se desenvolvia em sentido contrário, partindo da elaboração do cardápio e publicação das listas de compras, sem conhecer quais das demandas geradas nesse processo seriam passíveis de atendimento pelos agricultores. Essa nova lógica de trabalho favorece a intersetorialidade, o diálogo e, por conseguinte, o acesso dos agricultores familiares ao PNAE. Corrobora-se, assim, a importância de o nutricionista conhecer o que é produzido no município, o que contribui para que os cardápios sejam, de fato, elaborados de acordo com a vocação agrícola do local e respeitem o hábito alimentar da região, viabilizando a promoção do desenvolvimento local a partir do reconhecimento das potencialidades presentes no território.

Em primeiro lugar, a gente tinha que estar organizada, ter inspeção do serviço municipal e, para fornecer nota, tinha que ser sócio ou associar numa cooperativa. Também sempre ter produtos de qualidade para poder fornecer, né? (Agricultor, município F).

Por parte dos agricultores e da cooperativa, ficou clara a necessidade de se mobilizar com relação às adequações que a nova Lei exigia, principalmente as questões de qualidade, quantidade e atendimento às normas sanitárias, visto que não havia, até então, um processo de cobrança e fiscalização mais efetivo e sistematizado nesse sentido. As adequações sanitárias e a padronização foram exigências feitas pelos municípios para os agricultores iniciarem o fornecimento, impondo-Ihes um obstáculo a ser enfrentado, uma vez que alguns agricultores já eram fornecedores da alimentação escolar por meio do PAA, programa mais focado no escoamento da produção do que propriamente no atendimento desse tipo de requisito.

A participação também foi considerada relevante na implementação da Lei, sendo que cada ator social desempenha um papel importante nesse processo.

No planejamento de cardápio, a gente vê a questão de logística, entrega, faz visitas nas propriedades para poder saber o que está acontecendo, o que está produzindo e o que pode ser produzido e entregue também. (Nutricionista, município E).

Aos nutricionistas $(n=8)$ cabe intensa participação, sendo de sua responsabilidade a elaboração do cardápio e a descrição dos alimentos que serão objeto da chamada pública. A esse propósito, em alguns municípios, é o nutricionista quem elabora o edital de chamada pública, a pesquisa de preços, os cronogramas e a supervisão da entrega dos alimentos, além de prospectar e desenvolver fornecedores. Nesse sentido, constata-se o atarefamento e a dimensão da responsabilidade do profissional no âmbito do programa, sendo considerado elemento-chave na execução da Lei em todas as suas etapas.

Olha, quando o pessoal nos procura, a gente encaminha para conversar ali na Secretaria de Educação. Várias vezes aconteceu de os agricultores virem, dizerem que têm produto, aí a gente encaminha para a Secretaria de Educação. Eu já encaminhei direto para a cooperativa e também já repassei informações para a cooperativa, né? Mas, depois, eu não chego a acompanhar, porque já foge um pouco da nossa instância. (ATER, município B).

As equipes da ATER também têm participação relevante no processo de inclusão da agricultura familiar na alimentação escolar, pois identificam os agricultores que podem ser fornecedores e realizam a assistência técnica, contribuindo para qualificar tanto a gestão da propriedade quanto a da produção. 
Entre os municípios pesquisados, diferentes consumidores foram entrevistados: em dois municípios foram merendeiras e, nos demais, membros do CAE de variadas categorias (professores, diretores, representantes do Poder Executivo). A participação do consumidor no PNAE, nos municípios pesquisados, se dá, principalmente, com relação a ações de monitoramento e fiscalização, em termos da qualidade dos alimentos, prazos de validade e questões sanitárias. Contudo ressalta-se que, em alguns municípios, essa participação não é efetiva, e os CAE não desempenham seu papel. Cabe destacar que o CAE é um órgão colegiado de caráter fiscalizador, deliberativo e de assessoramento, que possui a finalidade de acompanhar e monitorar as diretrizes do programa e a aplicação dos recursos, zelar pela qualidade dos alimentos e receber o relatório anual do PNAE, devendo ser atuante para efetivar o controle social do programa, contribuindo para melhorar sua execução.

A gente acompanha para ver se o produto é de qualidade, se não está estragado, se está conforme discriminado na licitação... Isso tem que fazer, acompanhar. (Consumidor, Membro do CAE, município G).

Não, a única coisa é que a nutricionista nos repassa, nos avisa "olha, vai ter licitação, vocês estão convidados, podem participar"... Mas, como a gente trabalha, é muito difícil participar. Mas ela sempre comunica e, quando a gente tem reunião, também, ela diz "olha, chegou alface que não dava, fruta estragada e mandamos de volta". Nesse sentido que a gente fica sabendo, não que eu esteja lá quando chega o produto. (Consumidor, Membro do CAE, município $\mathrm{H}$ ).

Conforme indicado pelas falas, os membros do CAE não possuem conhecimento sobre seu papel de conselheiro e sobre a importância de sua atuação, identificando-se, na maioria dos municípios, que o CAE não parece ser atuante ou estar motivado para atuar de forma plena. Contrariamente, constatou-se um movimento de participação do CAE apenas em resposta a demandas geradas pelo nutricionista, a título de contribuição na resolução de algum problema específico ou de respaldo às decisões já adotadas por ele para fazer frente a questões pontuais. Ressalta-se, ainda, que os agricultores relataram não ter participação na implementação da Lei nos municípios pesquisados, evidenciando que não se reconhecem como protagonistas desse processo.

Não, a gente não participa porque nunca é chamado. A gente não vai lá se oferecer, não sabe nem que dia que eles fazem isso. (Agricultor, município F).

O agricultor familiar é ator social fundamental na implementação da Lei n. 11.947/2009, argumentando-se pela importância de que ele se perceba e atue como participante ativo do processo, envolvendo-se nos espaços de discussão e negociação. Um mecanismo de fortalecimento dessa participação pode vir do apoio dos nutricionistas para o empoderamento desses agricultores, promovendo sua inserção nas diferentes etapas do processo, e não só os reduzindo à condição de fornecedores ou entregadores de alimentos, alheios à dinâmica complexa imbricada com a alimentação escolar.

Surgem especialmente oportunas, nesse sentido, as ponderações de Jara (1998, p. 73):

O desenvolvimento local direciona toda intervenção institucional ao estudo do poder enquanto relação de forças sociais por meio das quais se processam as alianças e os confrontos, bem como as decisões. E isso nos leva a questões [...] como a democratização, a participação, o "empoderamento", as parcerias institucionais, o associativismo [...] Quando falamos de desenvolvimento local sustentável, por conseguinte, estamos falando de agricultores organi- 
zados e capacitados, ou seja, dotados de conhecimentos, habilidades e destrezas para que eles mesmos saibam e possam gerenciar e orientar seus assuntos, partindo dos recursos que realmente possuem. Estamos falando de um modelo mais endógeno [...], eficiente e mais sustentável do ponto de vista ambiental. Estamos falando de novos espaços (Conselhos) de diálogo, de deliberação, de controle [...].

\section{CONSIDERAÇÕES FINAIS}

Os resultados deste estudo indicam que os diferentes atores sociais percebem a importância da Lei n. 11.947/2009 para a alimentação escolar. A título de síntese, reforça-se que foram identificadas percepções sobre a Lei n. 11.947/2009 como favorecedora da oferta de alimentação saudável na escola. Além disso, a Lei surgiu como elemento de fortalecimento da agricultura familiar, ao oportunizar valoração social e geração de renda para o segmento, resultando em maior possibilidade de permanência da família no campo. Nesse contexto, o desenvolvimento local foi percebido como uma repercussão positiva da Lei, na medida em que ela incrementa a situação econômica do município e das famílias agricultoras.

Quanto à implementação da Lei n. 11.947/2009, foram apontados, com maior ou menor ênfase, diferentes fatores, sumarizados como iniciativa, mobilização e participação. A iniciativa foi apontada como tendo partido, principalmente, do nutricionista, em cuja figura esteve colocada a centralidade do processo. A mobilização dos demais atores se deu pelo emprego de dispositivos de divulgação, mapeamento da produção local e incentivo aos agricultores familiares para habilitarem-se ao fornecimento. Já no âmbito da participação, observou-se certa passividade de alguns atores - como os membros do CAE, em geral, pouco atuantes - e algum distanciamento dos técnicos da ATER, que revelaram uma atuação pouco articulada aos demais setores implicados. Além disso, chama a atenção o fato de os agricultores não se perceberem como atores no processo, o que certamente limita a produção de avanços mais expressivos na implementação da Lei.

Convém pontuar que a implementação é a fase em que uma política pública ganha materialidade. Porém, os atores envolvidos com a concretização da política não são, geralmente, os mesmos que a formularam. Assim, no nível local, a política se torna realidade a partir da leitura que fazem dela aqueles que a colocam em ação, em um movimento que não está isento de disputas e interesses dos mais diversos. Nessa perspectiva, preocupam as fragilidades observadas quanto à participação ativa dos atores envolvidos na implementação da Lei n. 11.947/2009, no que tange às questões afetas à agricultura familiar, visto que, apenas por meio de uma postura protagonista, podem ser fortalecidos mecanismos de qualificação desse processo nas mais diferentes realidades.

\section{REFERÊNCIAS}

ALMEIDA, L. M. M. C. et al. Políticas públicas, redes de segurança alimentar e agricultura familiar: elementos para construção de indicadores de eficácia. Estudos Sociedade e Agricultura, Rio de Janeiro, v. 14, n. 2, p. 205-235, out. 2006.

AZEVEDO, E; RIGON, S. A. Sistema alimentar com base no conceito de sustentabilidade. In: TADDEI, J. A.; LANG, R. M. F.; SILVA, G. L.; TOLONI, M. H. A. Nutrição em saúde pública. São Paulo: Rubio, 2010. p. 543-560

BRASIL. Ministério da Educação. Fundo Nacional de Desenvolvimento da Educação- FNDE. Aquisição de produtos da agricultura familiar para a alimentação escolar. 2. ed. Brasília: FNDE, 2016. 
. Resolução/CD/FNDE n. 4, de 2 de abril de 2015. Altera a redação dos artigos 25 a 32 da Resolução/ CD/FNDE n. 26, de 17 de junho de 2013, no âmbito do Programa Nacional de Alimentação Escolar (PNAE). Diário Oficial da União, Brasília, 03 abr. 2015. Seção 1, p. 10.

. Ministério da Educação. Fundo Nacional de Desenvolvimento da Educação (FNDE). Resolução n. 26, de 17 de junho de 2013. Dispõe sobre o atendimento da alimentação escolar aos alunos da educação básica no âmbito do Programa Nacional de Alimentação Escolar - PNAE. Diário Oficial da União, Brasília, 18 jun. 2013. Seção 1, p. 7.

Conselho Federal de Nutricionistas. Resolução/CFN n. 465, de 23 de agosto de 2010. Dispõe sobre as atribuições do Nutricionista, estabelece parâmetros numéricos mínimos de referência no âmbito do Programa de Alimentação Escolar (PAE) e dá outras providências. Diário Oficial da União, Brasília, 25 ago. 2010. Seção 1, p. 118

. Fundo Nacional de Desenvolvimento da Educação (FNDE). Lei n. 11.947, de 16 de junho de 2009. Dispõe sobre o atendimento da alimentação escolar e do Programa Dinheiro Direto na Escola. Diário Oficial da União, Brasília, 17 jun. 2009. Seção 1, p. 2.

Ministério da Saúde. Secretaria de Atenção à Saúde. Coordenação-Geral da Política de Alimentação e Nutrição. Guia alimentar para a população brasileira: promovendo a alimentação saudável. Brasília: Ministério da Saúde, 2008.

. Resolução/CD/FNDE n. 32, de 10 de agosto de 2006. Estabelece as normas para a execução do Programa Nacional de Alimentação Escolar-PNAE. Diário Oficial da União, Brasília, 11 ago. 2006. Seção 1, p. 22.

BUARQUE, S. C. Metodologia de planejamento do desenvolvimento local e municipal sustentável. Brasília: INCRA/IICA, 1999.

CARVALHO, D. G. de. O Programa Nacional de Alimentação Escolar e a sustentabilidade: o caso do Distrito Federal. 2009. 238 f. Dissertação (Mestrado em Desenvolvimento Sustentável) - Centro de Desenvolvimento Sustentável, Universidade de Brasília, Brasília, DF, 2009.

DOWBOR, L. et al. Políticas para o desenvolvimento local. São Paulo: Perseu Abramo, 2010.

FUNDO NACIONAL DO DESENVOLVIMENTO DA EDUCAÇÃO (FNDE). Dados físicos e financeiros do PNAE, 2015. Disponível em: <http://www.fnde.gov.br/programas/alimentacao-escolar/alimentacao-escolarconsultas/alimentacao-escolar-dados-f\%C3\%ADsicos-e-financeiros-do-pnae>. Acesso em: 15 jul. 2016.

GONZALEZ-CHICA, D. A. et al. Percepção dos cozinheiros escolares sobre o processo de utilização de produtos orgânicos na alimentação escolar em municípios catarinenses. Revista de Nutrição, Campinas, v. 26, n. 4, p. 407-418, jul./ago. 2013.

INSTITUTO BRASILEIRO DE GEOGRAFIA E ESTATÍSTICA (IBGE). Censo demográfico de 2010. Rio de Janeiro: IBGE, 2011. Disponível em:<http://www.brasileirosnomundo.itamaraty.gov.br/a-comunidade/estimativaspopulacionais-das-comunidades/estimativas-do-ibge/censo-demografico-ibge-2010.pdf>. Acesso em: 20 mar. 2015.

INSTITUTO NACIONAL DE ESTUDOS E PESQUISAS EDUCACIONAIS ANÍSIO TEIXEIRA (INEP). Censo Escolar, 2013. Disponível em: <http://portal.inep.gov.br/basica-censo>. Acesso em: 15 jul. 2016.

Censo Escolar, 2012. Disponível em: <http://portal.inep.gov.br/basica-censo>. Acesso em: 15 jul. 2016.

JARA, C. J. A sustentabilidade do desenvolvimento local: desafios de um processo em construção. Brasília: Instituto Interamericano de Cooperação para a Agricultura (IICA); Recife: Secretaria do Planejamento do Estado de Pernambuco (Seplan), 1998.

LEVY, R. B. et al. Distribuição regional e socioeconômica da disponibilidade domiciliar de alimentos no Brasil em 2008-2009. Revista de Saúde Pública, São Paulo, v. 46, n. 1, p. 6-15, fev. 2012.

MINAYO, M. C. S. O desafio do conhecimento: pesquisa qualitativa em saúde. 13. ed. São Paulo: HUCITEC, 2013. 
PIRES, L. H. A descentralização do poder e a regionalização das soluções como instrumentos de promoção do desenvolvimento local/regional. In: DOWBOR, L. et al. Políticas para o desenvolvimento local. São Paulo: Perseu Abramo, 2010. p. 105-130.

SANTOS, L. M. P. et al. Avaliação de políticas de segurança alimentar e combate à fome no período 19952002: 4- Programa Nacional de Alimentação Escolar. Cadernos de Saúde Pública, Rio de Janeiro, v. 23, n. 11, p. 2681-2693, nov. 2007.

SARAIVA, E. B. et al. Panorama da compra de alimentos da agricultura familiar para o Programa Nacional de Alimentação Escolar. Ciência e Saúde Coletiva, Rio de Janeiro, v. 18, n. 4, p. 927-935, abr. 2013.

SEN, A. Desenvolvimento como liberdade. São Paulo: Companhia das Letras, 2010.

SILVEIRA, C. Desenvolvimento local e novos arranjos socioinstitucionais: algumas referências para a questão da governança. In: DOWBOR, L. et al. Políticas para o desenvolvimento local. São Paulo: Perseu Abramo, 2010. p. 41-66.

SOARES, P. et al. Potencialidades e dificuldades para o abastecimento da alimentação escolar mediante a aquisição de alimentos da agricultura familiar em um município brasileiro. Ciência e Saúde Coletiva, Rio de Janeiro, v. 20, n. 6, p. 1891-1900, jun. 2015.

SUBIRATS, J.; KNOEPFEL, P.; LARRUE, C.; VARONNE, F. Análisis y gestión de políticas públicas. Barcelona: Ariel, 2008.

TRICHES, R. M; GERHARDT, T. E; SCHNEIDER, S. Políticas alimentares: interações entre saúde, consumo e produção de alimentos. Interações, Campo Grande, v. 15, n. 1, p. 109-120, jan./jun. 2014.

TURPIN, M. E. A alimentação escolar como fator de desenvolvimento local por meio do apoio aos agricultores familiares. Segurança alimentar e nutricional, Campinas, v. 16, n. 2, p. 20-42, jul./dez. 2009.

\section{Sobre as autoras:}

Márcia Pozzagnol Mossmann: Nutricionista. Mestre em Ciências da Saúde - Programa de Pós-Graduação stricto sensu em Ciências da Saúde da Universidade Comunitária da Região de Chapecó (UNOCHAPECÓ). Universidade Comunitária da Região de Chapecó - UNOCHAPECÓ.

E-mail: marciapozzagnol@unochapeco.edu.br

Carla Rosane Paz Arruda Teo: Doutora em Ciência de Alimentos pela Universidade Estadual de Londrina (UEL). Docente do Curso de Nutrição e do Programa de Pós-Graduação stricto sensu em Ciências da Saúde da Universidade Comunitária da Região de Chapecó (Unochapecó). Universidade Comunitária da Região de Chapecó - UNOCHAPECÓ. E-mail: carlateo@unochapeco.edu.br 
